\title{
Modeling the snow surface temperature with a one-layer energy balance snowmelt model
}

\author{
J. You ${ }^{1}$, D. G. Tarboton ${ }^{2}$, and C. H. Luce $^{3}$ \\ ${ }^{1}$ School of Natural Resources, University of Nebraska - Lincoln, Lincoln, Nebraska 68583, USA \\ ${ }^{2}$ Civil and Environmental Engineering, Utah State University, Logan, Utah 84322, USA \\ ${ }^{3}$ USDA Forest Service, Rocky Mountain Research Station, 322 E Front St., Boise, ID 83702, USA \\ Correspondence to: J. You (jyou2@unl.edu)
}

Received: 16 October 2013 - Published in Hydrol. Earth Syst. Sci. Discuss.: 10 December 2013

Revised: 6 October 2014 - Accepted: 30 October 2014 - Published: 11 December 2014

\begin{abstract}
Snow surface temperature is a key control on and result of dynamically coupled energy exchanges at the snow surface. The snow surface temperature is the result of the balance between external forcing (incoming radiation) and energy exchanges above the surface that depend on surface temperature (outgoing longwave radiation and turbulent fluxes) and the transport of energy into the snow by conduction and meltwater influx. Because of the strong insulating properties of snow, thermal gradients in snow packs are large and nonlinear, a fact that has led many to advocate multiple layer snowmelt models over single layer models. In an effort to keep snowmelt modeling simple and parsimonious, the Utah Energy Balance (UEB) snowmelt model used only one layer but allowed the snow surface temperature to be different from the snow average temperature by using an equilibrium gradient parameterization based on the surface energy balance. Although this procedure was considered an improvement over the ordinary single layer snowmelt models, it still resulted in discrepancies between modeled and measured snowpack energy contents. In this paper we evaluate the equilibrium gradient approach, the force-restore approach, and a modified force-restore approach when they are integrated as part of a complete energy and mass balance snowmelt model. The force-restore and modified forcerestore approaches have not been incorporated into the UEB in early versions, even though Luce and Tartoton have done work in calculating the energy components using these approaches. In addition, we evaluate a scheme for representing the penetration of a refreezing front in cold periods following melt. We introduce a method to adjust effective conductivity to account for the presence of ground near to a shallow
\end{abstract}

snow surface. These parameterizations were tested against data from the Central Sierra Snow Laboratory, CA, Utah State University experimental farm, UT, and subnivean snow laboratory at Niwot Ridge, CO. These tests compare modeled and measured snow surface temperature, snow energy content, snow water equivalent, and snowmelt outflow. We found that with these refinements the model is able to better represent the snowpack energy balance and internal energy content while still retaining a parsimonious one layer format.

\section{Introduction}

Snowmelt is an important source of water in the western United States and much of the world. Modeling snowmelt is important for water resource management and the assessment of spring snowmelt flood risk. The processes involved in snowmelt have been widely described (US Army Corps of Engineers, 1956; Gray and Male, 1981; Bras, 1990; Dingman, 1994; Linsley et al., 1975; Viessman et al., 2002). In snowmelt modeling, the heat flux between the snowpack and the atmosphere is partially governed by the snow surface temperature (Gray and Male, 1981; Dingman, 1994; Dozier, 1989) which depends on the conductive heat flux into the snow. Modeling conductive heat flux through the snowpack is a complex problem due to the changing nature of the snowpack through the influences of heating and cooling history. One of the primary reasons for the poor performance of single layer models in comparative validations is the poor representation of internal snowpack heat transfer processes (Blöschl and Kirnbauer, 1991; Koivasulo and Heikenkeimo, 
1999). Some snowmelt models use finite difference solutions of the heat equation (Anderson, 1976; Dickinson et al., 1993; Flerchinger and Saxton, 1989; Jordan, 1991; Yen, 1967). Possible inaccuracies in modeling the internal snowpack properties could lead to errors in estimating the snowpack and snow surface temperature (Colbeck and Anderson, 1982). Models such as CROCUS (Vionnet et al., 2012) have made considerable progress in representing the detail of within snow processes. There has also been recent progress towards using Richards equation to model meltwater flow in snow using multiple layers (Wever et al., 2014). However Wever et al. (2014) did note that there are challenging numerical issues associated with inhomogeneities in grain size and density, and precise quantification of the parameters that impact the model is a challenge. Furthermore, there is an increasing realization that lateral inhomogeneities in snowpacks are important (e.g., Wankiewicz, 1979; Higuchi and Tanaka, 1982; Kattelmann and Dozier, 1999; Williams et al., 2010; Eiriksson et al., 2013). These inhomogeneities result in lateral variability across a range of scales and fingering in the way that meltwater enters and flows through snow that is different from the matrix flow represented in one-dimensional finite difference solutions. This suggests that even our most complex snowpack models must seek a way to parameterize unmeasurable sub-element scale variability. In the single layer approach we model the surface temperature that provides the connection between the snow and the atmosphere above in a relatively straightforward way that avoids modeling the complexity of uncertain within snow processes.

Modeling needs a balance between representing details that are important to the purpose, or question being addressed and avoiding complexity and inaccuracy for details that are less important. There is no one right solution and in this paper we examine and evaluate single layer solutions that avoid some of the complexity of multilayer models for our purposes, which are the quantification of overall surface energy exchanges and meltwater produced by a snowmelt model for hydrological studies.

The Utah Energy Balance (UEB) snowmelt model (Tarboton et al., 1995; Tarboton and Luce, 1996; You, 2004) is a physically based point energy and mass balance model for snow accumulation and melt. The snowpack is characterized using two primary state variables, namely, snow water equivalent, $W,(\mathrm{~m})$ and the internal energy of the snowpack and top layer of soil, $U,\left(\mathrm{~kJ} \mathrm{~m}^{-2}\right)$. The physical basis of the model is the conservation of mass and energy. Snow surface temperature, a key variable in calculating latent and sensible heat fluxes and outgoing longwave radiation, is modeled using a thin surface skin or equilibrium gradient approach. The surface skin is assumed to have zero heat capacity. Snow surface temperature is calculated from the energy balance at the surface of the snowpack by equating incoming and outgoing fluxes between the snow mass and the air above; this allows the snow surface skin temperature to be different from the average temperature of the snowpack as reflected by the en- ergy content. This thus reflects the key insulating effect of snow on the surface energy balance without the introduction of additional layers and their resultant complexity and the potential for error where there is insufficient information to properly model this complexity.

The UEB model was initially tested against snow accumulation and melt measurements and was found to perform well. Later tests included comparisons against internal energy through measurement of the temperature profile in a snowpack (Tarboton, 1994). These tests indicated a discrepancy between the modeled and the measured internal energy (Tarboton, 1994; Tarboton and Luce, 1996). Luce (2000) and Luce and Tarboton (2010) analyzed the snowpack energy fluxes from a season of measurements collected at the Utah State University (USU) drainage farm (USUDF) in Cache Valley, Utah to evaluate the reasons for the discrepancies in the internal energy. One cause was the estimation of longwave radiation inputs based on air temperatures in an environment subject to frequent temperature inversions and resultant fog. Another cause of the discrepancies was the parameterization of snow surface temperature. These problems had been offsetting each other in a way that when the longwave radiation inputs were corrected, the modeled surface temperatures no longer matched measurements. To address this problem, Luce (2000) and Luce and Tarboton (2001, 2010) evaluated various alternative parameterizations against the currently used equilibrium gradient approach. These included the force-restore approach (e.g., Deardorff, 1978; Dickinson et al., 1993; Hu and Islam, 1995) and a modified force-restore approach that was suggested (Luce, 2000; Luce and Tarboton, 2001, 2010) to improve the representation of snow surface temperature and help improve the representation of energy content in the snowpack. However these evaluations were driven by measured surface temperature and did not include coupled modeling of the snow energy balance driven by atmospheric forcing. In this paper these suggestions are implemented and tested within the UEB snowmelt model.

Snowmelt generated at the snow surface is initially held in the snowpack as liquid water up to the liquid holding capacity. When the surface forcing changes to cooling, this water refreezes and a refreezing front penetrates into the snow. The rate of penetration of the refreezing front is governed by the rate of heat loss, the latent heat of fusion, and the temperature gradient in the layer above the refreezing front. The original UEB model (Tarboton, 1994; Tarboton and Luce, 1996) used the equilibrium gradient approach to estimate snow surface temperature and did not account for the presence of liquid water during refreezing periods with the result that the snow surface temperature is modeled as too low with too little heat loss during these periods. Multiple-layer snow models (e.g., Flerchinger and Saxton, 1989; Jordan, 1991) account for this effect because the liquid content and temperature of each layer is explicitly represented. Here we present and test a formulation for representing this refreezing effect in the single 
layer UEB model. In addition to the two changes mentioned above we also introduce a method to adjust the effective thermal conductivity of shallow snowpacks to account for the combined effect of snow and the ground below the snow.

\section{Model description}

\subsection{Mass and energy balance equations}

The original UEB model is described by Tarboton et al. (1995) and Tarboton and Luce (1996). Here we evaluate modifications introduced to refine the representation of surface temperature, including the modified force-restore approach, refreezing of liquid water and conductivity adjustments for shallow snow (You, 2004). In separate work, we have evaluated the addition of a vegetation layer to UEB (Mahat and Tarboton, 2012; Mahat et al., 2013). We refer to the Tarboton et al. (1995) model as the original UEB model. The model examined here we refer to as surface UEB. This is a single layer model used to model snow accumulation in the open. Surface UEB is also the beneath canopy layer of vegetation UEB a two layer model for snow accumulation and melt in forested environments that was evaluated by Mahat and Tarboton (2012) and Mahat et al. (2013). A comprehensive review of the surface layer model is given here so that the reader can understand the context for the modifications that were made. Where we do not use a qualifier the methods are the same in surface UEB and the original UEB.

In the UEB model (Tarboton et al., 1995; Tarboton and Luce, 1996), the time evolution of the snowpack is driven by the energy exchange between the snowpack, the air above and the soil below according to mass and energy balance equations through snow water equivalent, $W$, and energy content, $U$,

$$
\begin{aligned}
\frac{\mathrm{d} U}{\mathrm{~d} t} & =Q_{\mathrm{sn}}+Q_{\mathrm{li}}-Q_{\mathrm{le}}+Q_{\mathrm{p}}+Q_{\mathrm{g}}+Q_{\mathrm{h}} \\
& +Q_{\mathrm{e}}-Q_{\mathrm{m}},\left(\mathrm{kJ} \mathrm{m}^{-2} \mathrm{~h}^{-1}\right) \\
\frac{\mathrm{d} W}{\mathrm{~d} t} & =P_{\mathrm{r}}+P_{\mathrm{s}}-M_{\mathrm{r}}-E,\left(\mathrm{mh}^{-1}\right),
\end{aligned}
$$

where $Q_{\mathrm{sn}}$ is the net shortwave energy received by the snowpack, $Q_{\mathrm{li}}$ is the incoming longwave radiation, $Q_{\mathrm{le}}$ is outgoing longwave radiation, $Q_{\mathrm{p}}$ is the energy advected by precipitation into the snow, $Q_{\mathrm{g}}$ is the ground heat flux to the combination of snow and the upper layer of soil, $Q_{\mathrm{h}}$ is the sensible heat flux to/from the snow with sign convention that flux to the snow is positive, $Q_{\mathrm{e}}$ is the latent heat flux to/from the snow with sign convention that flux to the snow is positive, and $Q_{\mathrm{m}}$ is the advected heat removed by meltwater. $P_{\mathrm{r}}$ is the rate of precipitation as rain; $P_{\mathrm{S}}$ is the rate of precipitation as snow; $M_{\mathrm{r}}$ is the meltwater outflow rate; and $E$ is the sublimation rate; $t$ is time (h). Internal energy $U$ is not defined relative to absolute zero, but rather relative to the melting point. $U$ is thus taken as $0 \mathrm{~kJ} \mathrm{~m}^{-2}$ when the snowpack is frozen at $0{ }^{\circ} \mathrm{C}$ and contains no liquid water. With this definition negative internal energies correspond to the cold content (e.g., Dingman, 1994, p. 182), and positive internal energies reflect change in phase of some fraction of snow from frozen to liquid. The model requires inputs of air temperature, wind speed, humidity, and incident radiation that are used to drive the energy balance, and precipitation that is used to drive the mass balance. Precipitation is partitioned into snowfall or rainfall based upon air temperature (US Army Corps of Engineers, 1956). In locations where snow is subject to redistribution due to wind blown drifting or sliding, an accumulation factor (Tarboton et al., 1995; Tarboton and Luce, 1996; Luce et al., 1998) is used to adjust the snowfall inputs.

The use of energy content as a state variable means that the model does not explicitly prognose snowpack temperature. Since snowpack temperature is important for energy fluxes into the snow, it needs to be obtained diagnostically from internal energy and snow water equivalent as follows:

If $U<0, T_{\mathrm{ave}}=U /\left(\rho_{\mathrm{w}} W C_{\mathrm{i}}+\rho_{\mathrm{g}} D_{\mathrm{e}} C_{\mathrm{g}}\right)$, All solid phase,
If $0<U<\rho_{\mathrm{w}} W h_{\mathrm{f}}, T_{\mathrm{ave}}=0^{\circ} \mathrm{C}$, with $L_{\mathrm{f}}=U /\left(\rho_{\mathrm{w}} h_{\mathrm{f}} W\right)$,

Solid and liquid mixture

If $U>\rho_{\mathrm{w}} W h_{\mathrm{f}}, \quad T_{\mathrm{ave}}=\frac{U-\rho_{\mathrm{w}} W h_{\mathrm{f}}}{\rho_{\mathrm{g}} D_{\mathrm{e}} C_{\mathrm{g}}+\rho_{\mathrm{w}} W C_{\mathrm{w}}}$, All liquid.

In the equations above, $T_{\text {ave }}$ denotes snowpack average temperature $\left({ }^{\circ} \mathrm{C}\right), h_{\mathrm{f}}$ denotes the latent heat of fusion $\left(333.5 \mathrm{~kJ} \mathrm{~kg}^{-1}\right), \rho_{\mathrm{w}}$ the density of water $\left(1000 \mathrm{~kg} \mathrm{~m}^{-3}\right), C_{\mathrm{i}}$ the specific heat of ice $\left(2.09 \mathrm{~kJ} \mathrm{~kg}^{-1}{ }^{\circ} \mathrm{C}^{-1}\right), \rho_{\mathrm{g}}$ the soil density, $C_{\mathrm{g}}$ the specific heat of soil, $C_{\mathrm{w}}$ the specific heat of water $\left(4.18 \mathrm{~kJ} \mathrm{~kg}^{-1}{ }^{\circ} \mathrm{C}^{-1}\right), D_{\mathrm{e}}$ the depth of soil that interacts thermally with the snowpack and $L_{\mathrm{f}}$ the liquid fraction by mass. The basis for Eq. (3a)-(c) is that the heat required to melt the entire snow water equivalent at $0^{\circ} \mathrm{C}$ is $\rho_{\mathrm{w}} W h_{\mathrm{f}}\left(\mathrm{kJ} \mathrm{m}^{-2}\right)$. Where $U$ is between 0 and this quantity, the liquid fraction is determined by proportioning, i.e., $L_{\mathrm{f}}=U /\left(\rho_{\mathrm{w}} h_{\mathrm{f}} W\right)$. The heat capacity of the snow combined with thermally interacting soil layer is $\rho_{\mathrm{w}} W C_{\mathrm{i}}+\rho_{\mathrm{g}} D_{\mathrm{e}} C_{\mathrm{g}}\left(\mathrm{kJ}^{\circ} \mathrm{C}^{-1} \mathrm{~m}^{-2}\right)$, so in the case that $U<0$, dividing $U$ by this combined heat capacity gives $T_{\text {ave }}$. Where $U>\rho_{\mathrm{w}} W h_{\mathrm{f}}$, the snow contains sufficient energy to melt completely, and the temperature of the remaining liquid phase is given by Eq. (3c). Practically, the condition in Eq. (3c) only occurs when $W$ is zero since a completely liquid snowpack cannot exist; it becomes melt runoff. Nevertheless, this equation is included for completeness to keep track of the energy content during periods of intermittent snow cover. With $T_{\text {ave }}$ representing the temperature of the ground, Eq. (3c) handles the possibility of snowfall melting immediately due to coming in contact with warm ground.

The net shortwave radiation is calculated from incident shortwave radiation and albedo calculated as a function of snow age and solar illumination angle following Dickinson et al. (1993). The incident shortwave radiation is either 
measured or estimated from the diurnal temperature range (Bristow and Campbell, 1984). On sloping surfaces, incident radiation is adjusted for slope and aspect (e.g., Dingman, 1994).

In the albedo model, which follows Dickinson et al. (1993) and is described in detail in Tarboton and Luce (1996), the dimensionless age of the snow surface, $\tau$, is retained as a state variable, and is updated with each time step, dependent on snow surface temperature and snowfall. Reflectance is computed for two bands; visible $(<0.7 \mu \mathrm{m})$ and near infrared $(>0.7 \mu \mathrm{m})$ with adjustments for illumination angle and snow age. Then albedo is taken as the average of the two reflectances. A parameter $d_{\text {NewS }}(\mathrm{m})$ represents the depth of snowfall that is assumed to restore the snow surface to new conditions $(\tau=0)$. With snowfall, $P_{\mathrm{S}}$, less than $d_{\text {NewS }}$ in a time step the dimensionless age is reduced by a factor (1$\left.P_{\mathrm{s}} / d_{\text {NewS }}\right)$

When the snowpack is shallow (depth $z<h=0.1 \mathrm{~m}$ ) the effective surface albedo, $A$, is taken as $r_{\alpha} \alpha_{\mathrm{bg}}+\left(1-r_{\alpha}\right) \alpha_{\mathrm{s}}$ where $r_{\alpha}=(1-z / h) e^{-z / 2 h}$. This interpolates between the snow albedo, $\alpha_{\mathrm{s}}$, and bare ground albedo, $\alpha_{\mathrm{bg}}$, with the exponential term approximating the exponential extinction of radiation penetration of snow scaled to $1 / e^{2}$ at depth $h$.

The incident longwave radiation is estimated based on air temperature, $T_{\mathrm{a}}(\mathrm{K})$ using the Stefan-Boltzmann equation. The emissivity of air is estimated using Satterlund's (1979) equation for clear conditions. The presence of clouds increases downward longwave radiation. This is modeled by estimating the cloud cover fraction based on the Bristow and Campbell (1984) atmospheric transmission factor (see details in Tarboton and Luce, 1996). The outgoing longwave radiation is calculated from the snow surface temperature using the Stefan-Boltzmann equation, with emissivity of snow, $\varepsilon_{\mathrm{s}}$, taken as 0.99 .

The latent heat flux, $Q_{\mathrm{e}}$ and sensible heat flux, $Q_{\mathrm{h}}$ are modeled using bulk aerodynamic formulae (Anderson, 1976):

$Q_{\mathrm{h}}=\rho_{\mathrm{a}} C_{\mathrm{p}}\left(T_{\mathrm{a}}-T_{\mathrm{s}}\right) K_{\mathrm{h}}$

and

$Q_{\mathrm{e}}=\rho_{\mathrm{a}} h_{\mathrm{v}}\left(q_{\mathrm{s}}-q_{\mathrm{a}}\right) K_{\mathrm{e}}$,

where $\rho_{\mathrm{a}}$ is the density of air, $C_{\mathrm{p}}$ is the specific heat of air at constant pressure $\left(1.005 \mathrm{~kJ} \mathrm{~kg}^{-1}{ }^{\circ} \mathrm{C}^{-1}\right), h_{\mathrm{v}}$ is the latent heat of vaporization (sublimation) of ice $\left(2834 \mathrm{~kJ} \mathrm{~kg}^{-1}\right), q_{\mathrm{a}}$ is the air specific humidity, $q_{\mathrm{s}}$ is the specific humidity at the snow surface which is assumed to be saturated relative to the vapor pressure over ice (e.g., Lowe, 1977), and $K_{\mathrm{h}}$ and $K_{\mathrm{e}}$ are turbulent transfer conductances for sensible and latent heat respectively. Under neutral atmospheric conditions $K_{\mathrm{e}}$ and $K_{\mathrm{h}}$ are given by

$$
K_{\mathrm{n}}=\frac{k_{\mathrm{v}}^{2} u}{\left[\ln \left(z_{\mathrm{m}} / z_{0}\right)\right]^{2}},
$$

where $z_{\mathrm{m}}$ is the measurement height for wind speed, air temperature, and humidity, $u$ is the wind speed, $k_{\mathrm{v}}$ is von Kármán's constant (0.4), and $z_{0}$ is the aerodynamic roughness. When there is a temperature gradient near the surface, buoyancy effects may enhance or dampen the turbulent transfers, necessitating adjustments to $K_{\mathrm{n}}$. We use

$K_{\mathrm{h}}=K_{\mathrm{n}} \frac{1}{\Phi_{\mathrm{M}} \Phi_{\mathrm{H}}}$

and

$K_{\mathrm{e}}=K_{\mathrm{n}} \frac{1}{\Phi_{\mathrm{M}} \Phi_{\mathrm{E}}}$,

where $\Phi_{\mathrm{M}}, \Phi_{\mathrm{H}}, \Phi_{\mathrm{E}}$ are the stability functions for momentum, sensible heat, and water vapor, respectively. The stability functions are estimated using the bulk Richardson number:

$R_{i}=\frac{g z_{\mathrm{m}}\left(T_{\mathrm{a}}-T_{\mathrm{s}}\right)}{\frac{1}{2}\left(T_{\mathrm{a}}+T_{\mathrm{s}}\right) u^{2}}$

where $g$ is gravity acceleration $\left(9.8 \mathrm{~m} \mathrm{~s}^{-2}\right)$. For stable conditions $\left(R_{i}>0\right)$, we use the approximation of Price and Dunne (1976),

$\frac{1}{\Phi_{\mathrm{M}} \Phi_{\mathrm{H}}}=\frac{1}{\Phi_{\mathrm{M}} \Phi_{\mathrm{E}}}=\frac{1}{1+10 R_{i}}$.

For unstable conditions $\left(R_{i}<0\right)$ we use (Dyer and Hicks, 1970; Anderson, 1976; Jordan, 1991),

$\frac{1}{\Phi_{\mathrm{M}} \Phi_{\mathrm{H}}}=\frac{1}{\Phi_{\mathrm{M}} \Phi_{\mathrm{E}}}=\left(1-16 R_{i}\right)^{0.75}$.

Because information for estimating turbulence under extremely unstable conditions is poor, we capped the value of $1 / \Phi_{\mathrm{M}} \Phi_{\mathrm{H}}$ at 3 , which occurs near $R_{i}=-0.2$. Anderson (1976) shows that iterative solutions of Deardorff's (1968) empirical equations begin to level off for more strongly unstable situations as the value of 3 is approached. Strongly unstable conditions are rare over snow, but this is in the model code for completeness. These stability corrections assume that sensible and latent heat transfer coefficients are equal, $K_{\mathrm{h}}=K_{\mathrm{e}}$.

\subsection{Original quantification of surface energy flux}

An important characteristic of the UEB model is its separate representation of surface temperature and average snowpack temperature. This facilitates reasonable modeling of surface energy exchanges that depend on snow surface temperature, while retaining a parsimonious single layer model. In this paper we apply new parameterizations for the snow surface temperature introduced by Luce and Tarboton (2010) and test them in the context of a full surface energy balance. The sum 
of energy fluxes in Eq. (1) from above the snowpack are referred to as the surface energy forcing.

$Q_{\text {forcing }}\left(T_{\mathrm{s}}\right)=Q_{\mathrm{sn}}+Q_{\mathrm{li}}+Q_{\mathrm{h}}\left(T_{\mathrm{s}}\right)+Q_{\mathrm{e}}\left(T_{\mathrm{s}}\right)+Q_{\mathrm{p}}-Q_{\mathrm{le}}\left(T_{\mathrm{S}}\right)$

The sensible heat, latent heat, and outgoing longwave radiation are functionally dependent on the surface temperature, $T_{\mathrm{S}}$. In the original model, the heat conducted into the snow, $Q_{\text {cs }}$, is calculated as a function of the snow surface temperature, $T_{\mathrm{S}}$, and average snowpack temperature, $T_{\mathrm{ave}}$.

$Q_{\mathrm{cs}}\left(T_{\mathrm{s}}, T_{\mathrm{ave}}\right)=k \rho_{\mathrm{s}} C_{\mathrm{i}} \frac{\left(T_{\mathrm{s}}-T_{\mathrm{ave}}\right)}{Z_{\mathrm{e}}}=K_{\mathrm{s}} \rho_{\mathrm{s}} C_{\mathrm{i}}\left(T_{\mathrm{s}}-T_{\mathrm{ave}}\right)$,

where $\rho_{\mathrm{s}}$ is the snow density $\left(\mathrm{kg} \mathrm{m}^{-3}\right), k$ the snow thermal diffusivity $\left(\mathrm{m}^{2} \mathrm{~h}^{-1}\right), Z_{\mathrm{e}}$ the effective depth over which the temperature gradient acts $(\mathrm{m})$, and $K_{\mathrm{s}}=k / Z_{\mathrm{e}}$ is termed snow surface conductance. In the original model, because there is uncertainty in values for $Z_{\mathrm{e}}$ and $k, K_{\mathrm{s}}$ was used as a calibration parameter.

The energy balance at the surface is given by

$Q_{\mathrm{cs}}\left(T_{\mathrm{s}}, T_{\text {ave }}\right)=Q_{\text {forcing }}\left(T_{\mathrm{s}}\right)$.

Equation (14) is solved numerically for $T_{\mathrm{S}}$ using the NewtonRaphson method backed up by a more robust bisection approach. The Newton-Rhapson scheme is used first because it is more efficient. It tests for convergence and in time steps (a small percentage depending on the data) when it does not converge, the model resorts to a more robust bisection approach that is guaranteed to converge because the equation giving temperature flux into the snow based on surface temperature is monotonic. This is the case for all the surface temperature parameterizations evaluated. Thus the new approach for surface temperature does not alter the numerical stability. Physically, $T_{\mathrm{S}}$ is constrained to be no greater than $0{ }^{\circ} \mathrm{C}$ when there is snow present. When the equilibrium solution produces a solution of $T_{\mathrm{s}}>0^{\circ} \mathrm{C}$, this means that conduction into the snow cannot accommodate all the energy input through surface forcing, and the extra energy will produce meltwater at the surface, which then infiltrates into the lower parts of the snowpack and, if $U<0$, refreezes, representing the meltwater advection process for transport of energy into the snow. In these cases the surface energy flux terms in Eq. (1) are calculated using $T_{\mathrm{S}}=0^{\circ} \mathrm{C}$ to model the snow energy content change.

\section{Alternative models of surface heat conduction}

Heat flow in a snowpack can be described using the diffusive heat transfer equation and assuming homogeneity of snow properties (Yen, 1967)

$$
\frac{\partial T}{\partial t}=k \frac{\partial^{2} T}{\partial z^{2}}
$$

where $T$ is the temperature $\left({ }^{\circ} \mathrm{C}\right), z$ is depth relative to snow surface $(\mathrm{m})$, and $k$ is the thermal diffusivity of snow $\left(\mathrm{m}^{2} \mathrm{~h}^{-1}\right)$. Thermal diffusivity is related to thermal conductivity and specific heat by

$k=\frac{\lambda}{C_{\mathrm{i}} \rho_{\mathrm{s}}}$,

where $\lambda$ is the thermal conductivity of snow $\left(\mathrm{kJ} \mathrm{m}^{-1} \mathrm{~K}^{-1} \mathrm{~h}^{-1}\right)$. For semi-infinite boundary conditions $(0<z<\infty)$ with sinusoidal temperature fluctuation at the upper boundary $(z=0)$,

$T(0, t)=\langle T\rangle+A \sin (\omega t)$.

The differential Eq. (15) has solution (Berg and McGregor, 1966):

$T(z, t)=\langle T\rangle+A e^{-\frac{z}{d}} \sin \left(\omega_{1} t-\frac{z}{d}\right)$.

In this solution, $A$ is the amplitude of the imposed temperature fluctuation at the surface, $\omega$ is the frequency, $\langle T\rangle$, the average about which surface temperature fluctuations are centered, and $d$ is the damping depth for a given frequency. At the snow surface, the primary forcing is diurnal, suggesting $\omega=\omega_{1}=2 \pi / 24 \mathrm{~h}^{-1}$, with the damping depth, $d=d_{1}=$ $\sqrt{\frac{2 k}{\omega_{1}}}$, corresponding to frequency $\omega_{1}$.

Equation (18) indicates that temperature oscillations are damped by a factor $1 / e$ for each increment of depth $d_{1}$, and the time-averaged temperature at each depth is $\langle T\rangle$. Equation (18) can be differentiated on the depth $(z)$ to evaluate the temperature gradient, and the surface energy flux (at $z=0$ ) can be written as

$Q_{\mathrm{cs}}=-\lambda \frac{\partial T}{\partial z}(0, t)=\frac{\lambda A}{d_{1}}\left[\sin \left(\omega_{1} t\right)+\cos \left(\omega_{1} t\right)\right]$.

Recognizing that $\omega_{1} \cos \left(\omega_{1} t\right)$ is the derivative of $\sin \left(\omega_{1} t\right)$ with respect to $t$, and substituting Eq. (17) and its time derivative into Eq. (19) yields

$Q_{\mathrm{cs}}=\frac{\lambda}{d_{1} \omega_{1}} \frac{\partial T}{\partial t}(0, t)+\frac{\lambda}{d_{1}}(T(0, t)-\langle T\rangle)$.

This expresses the surface heat flux as a function of both the time derivative of surface temperature and the difference between the current surface temperature and the time averaged surface temperature (Luce and Tarboton, 2010). This analytic solution for the simplified setting of a semi-infinite domain with sinusoidal surface temperature forcing serves as the basis for the numerical approximations of surface temperature, $T_{\mathrm{s}}$, that are evaluated.

\subsection{Equilibrium gradient approach}

The original equilibrium gradient method of surface temperature parameterization used in Eq. (13) can be seen to be an 
approximation to Eq. (20) that ignores the time derivative of the surface temperature term and approximates the average temperature at the surface over time, $\langle T\rangle$, by the snowpack average temperature, $T_{\text {ave }}$, while using actual surface temperature, $T_{\mathrm{s}}$, in place of the sinusoidal forcing $T(0, t)$. This method approximates the energy flux as a gradient between the surface temperature and average temperature of snow over an effective distance $Z_{\mathrm{e}}$, equivalent to $d_{1}$. In the original UEB model, $Z_{\mathrm{e}}$ was absorbed into the parameter $K_{\mathrm{s}}$ that was calibrated, however here $d_{1}$ is related to the diurnal frequency, so to retain this calibration capability we use $Z_{\mathrm{e}}=\mathrm{rd}_{1}$ (i.e., the damping depth $d_{1}$ scaled by a dimensionless adjustable parameter $r$ ) and write Eq. (13) in the form showing the similarity to Eq. (20):

$Q_{\mathrm{cs}}=\frac{\lambda}{r d_{1}}\left(T_{\mathrm{s}}-T_{\mathrm{ave}}\right)$.

\subsection{Force-restore approach}

The force-restore parameterization (e.g., Deardorff, 1978; Dickinson et al., 1993; Hu and Islam, 1995) is

$$
Q_{\mathrm{cs}}=\frac{\lambda}{d_{1}} \frac{1}{\omega_{1} \Delta t}\left(T_{\mathrm{s}}-T_{\mathrm{s} \mathrm{lag} 1}\right)+\frac{\lambda}{r d_{1}}\left(T_{\mathrm{s}}-T_{\mathrm{ave}}\right),
$$

(Luce and Tarbton, 2010). Here $\Delta t$ is the time step and $T_{\text {slag1 }}$ is the surface temperature of snow in the previous time step. A finite difference approximation has been used for the time derivative and $\langle T\rangle$ has been replaced by the depth average snowpack temperature $T_{\text {ave }}$. Again, we have scaled the damping depth by a parameter $r$.

\subsection{Modified force-restore approach}

Luce (2000) and Luce and Tarboton $(2001,2010)$ found that the diurnal cycle may be superimposed on a temperature gradient that varied at longer weekly to seasonal time scales, causing variations in the temperature gradient and heat fluxes with depth. Luce (2000) and Luce and Tarboton (2001, 2010) suggested that the heat flux and the surface temperature could be estimated using the following modification to the forcerestore equation:

$Q_{\mathrm{cs}}=\frac{\lambda}{d_{1}} \frac{1}{\omega_{1} \Delta t}\left(T_{\mathrm{s}}-T_{s_{\text {lag } 1}}\right)+\frac{\lambda}{r d_{1}}\left(T_{\mathrm{s}}-\bar{T}_{\mathrm{s}}\right)+\frac{\lambda}{d_{\mathrm{lf}}}\left(\bar{T}_{\mathrm{s}}-\bar{T}_{\mathrm{ave}}\right)$,

where $\bar{T}_{\mathrm{S}}$ is the average surface temperature estimated for the previous $24 \mathrm{~h}$, and $\bar{T}_{\text {ave }}$ is the $24 \mathrm{~h}$ time average of the depth average snowpack temperature. The $3 \mathrm{rd}$ term represents the superimposed gradient, a lower frequency effect, approximated using an equilibrium gradient approach similar to Eq. (21). In this parameterization $d_{\mathrm{lf}}$ is the damping depth associated with the longer time scale forcing having lower frequency $\omega_{\mathrm{lf}}$, i.e., $d_{\mathrm{lf}}=\sqrt{\frac{2 k}{\omega_{\mathrm{lf}}}}$. In Eq. (23) since the appropriate low frequency parameter $\left(\omega_{\mathrm{lf}}\right)$ is not known a priori, Luce $(2000)$ and Luce and Tarboton $(2001,2010)$ suggested that $d_{\mathrm{lf}}$ be calibrated.

\subsection{Theory of meltwater refreezing}

The approaches described above solve for surface temperature based upon a balance between surface forcing and the capacity of the snow near the surface to conduct heat into or out of the snowpack. However, during a cooling period following melting where there is liquid water present in the snow, the depression of snow surface temperature is inhibited by the energy required to refreeze liquid water near the surface before a temperature gradient can be established and conduction can occur. The net effect of this is that when there is liquid water present the snow surface stays warmer longer and heat loss at night and in cooling periods is more rapid. To accommodate this effect we have developed a parameterization for the penetration of a refreezing front and conduction of heat between the surface and refreezing front while there is liquid water present in the snow.

When snow energy content $U$ is greater than 0 , liquid water exists in the snowpack. The snowpack is assumed to be isothermal at $0{ }^{\circ} \mathrm{C}$. Using the relationship between energy content and liquid fraction (Eq. 3b), the equivalent depth of liquid water in the snowpack $w_{\mathrm{m}}(\mathrm{m})$ is calculated as

$w_{\mathrm{m}}=L_{\mathrm{f}} W=\frac{U}{\rho_{\mathrm{w}} h_{\mathrm{f}}}$.

The capillary holding capacity of the snow is defined as mass fraction liquid holding capacity, $L_{\mathrm{c}}$, times snow water equivalent $L_{\mathrm{c}} W$, which implies that the maximum density of capillary water, $\rho_{\mathrm{m}}$, is $\rho_{\mathrm{m}}=\frac{L_{\mathrm{c}} W \rho_{\mathrm{w}}}{D}=L_{\mathrm{c}} \rho_{\mathrm{s}}$, where $D$ is the depth of the snowpack. We assume that prior to melt outflow, when the liquid water content is less than the capillary holding capacity, the meltwater is held at the maximum density of capillary water in the upper portion of the snowpack. The justification for this assumption is that energy generating melt primarily originates at the surface. With this assumption the depth to which meltwater has penetrated is

$d_{\mathrm{w}}=\frac{w_{m} \rho_{\mathrm{w}}}{\rho_{\mathrm{m}}}=\frac{U}{\rho_{\mathrm{w}} h_{\mathrm{f}}} \frac{\rho_{\mathrm{w}}}{\rho_{\mathrm{m}}}=\frac{U}{\rho_{\mathrm{m}} h_{\mathrm{f}}}$.

This describes the state of the snowpack prior to the onset of a refreezing episode during which $Q_{\text {forcing }}$ is negative. The negative forcing will result in refreezing that penetrates down from the surface as illustrated in Fig. 1. The rate of increase of the depth to the refreezing front, $d_{\mathrm{r}}$, is given by

$\frac{d d_{\mathrm{r}}}{\mathrm{d} t}=-\frac{Q\left(T_{\mathrm{s}}\right)}{\rho_{\mathrm{m}} h_{\mathrm{f}}}$,

where $Q\left(T_{\mathrm{s}}\right)$ is the heat flux just above the refreezing front, here indicated to be a function of surface temperature $T_{\mathrm{s}}$. The sign convention is that heat flux is positive into the snow which is why there is a negative sign in Eq. (26).

We assume a linear temperature gradient above the refreezing front with $Q\left(T_{\mathrm{S}}\right)$ given by

$Q\left(T_{\mathrm{s}}\right)=\lambda \frac{T_{\mathrm{s}}}{d_{\mathrm{r}}}$. 


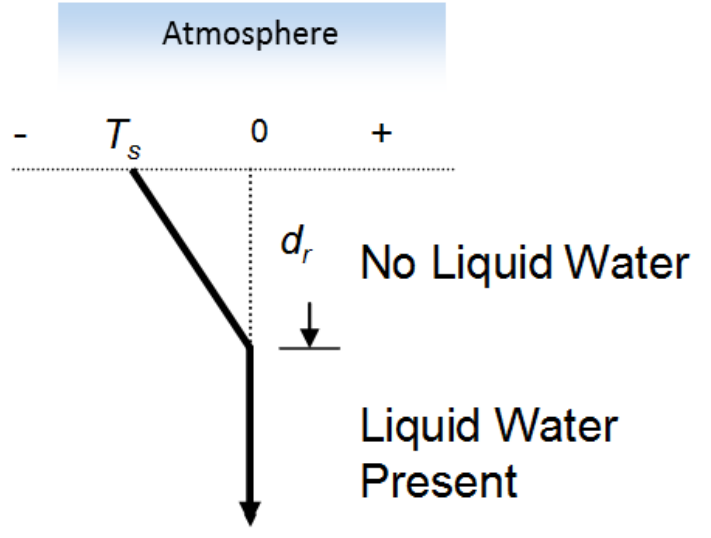

Figure 1. Schematic illustration of temperature profile during the downward propagation of a refreezing front.

We use an equilibrium approach for surface temperature that balances the surface forcing with the conduction into the snow above the refreezing front, neglecting any heat stored in the snow between the refreezing front and the surface (as this will be small because the heat capacity of snow is less than the latent heat of fusion). This is written

$Q\left(T_{\mathrm{s}}\right)=Q_{\text {forcing }}\left(T_{\mathrm{s}}\right)$.

To solve for $d_{\mathrm{r}}(t)$ the dependence of $Q_{\text {forcing }}\left(T_{\mathrm{S}}\right)$ on $T_{\mathrm{s}}$ is linearized,

$Q_{\text {forcing }}\left(T_{\mathrm{s}}\right)=a-b T_{\mathrm{s}}$.

Here $a$ is the forcing surface energy flux when the surface temperature of snow is $0^{\circ} \mathrm{C}$, and $b$ is the slope of surface forcing flux to surface temperature function. This is a positive value since $Q\left(T_{\mathrm{S}}\right)$ decreases with $T_{\mathrm{s}} . a$ is obtained by putting $T_{\mathrm{s}}=0$ into $Q_{\text {forcing }}\left(T_{\mathrm{s}}\right) . b$ is obtained by putting a small negative (below freezing) $T_{\mathrm{S}}$ into $Q_{\text {forcing }}\left(T_{\mathrm{S}}\right)$ and solving Eq. (29). If $a$ is greater than 0, then the surface forcing is positive and meltwater is being generated at the surface so $d_{\mathrm{r}}$ is set to 0 . When $a$ becomes less than 0 , the snowpack starts refreezing. Combining Eqs. (27) and (29) gives

$\frac{\lambda}{d_{\mathrm{r}}} T_{\mathrm{s}}=a-b T_{\mathrm{s}}$

$T_{\mathrm{S}}$ can then be expressed as

$T_{\mathrm{S}}=\frac{a}{\frac{\lambda}{d_{\mathrm{r}}}+b}$.

Substituting this $T_{\mathrm{S}}$ into (27) then the result into (26) gives

$\frac{\mathrm{d} d_{\mathrm{r}}}{\mathrm{d} t}=-\frac{\lambda a}{\rho_{\mathrm{m}} h_{\mathrm{f}}\left(\lambda+b d_{\mathrm{r}}\right)}$.

Integrating Eq. (32) starting from the initial refreezing depth $d_{\mathrm{r} 1}$ during a time step, we get

$\lambda d_{\mathrm{r}}+\frac{b}{2} d_{\mathrm{r}}^{2}-\left(\lambda d_{\mathrm{r} 1}+\frac{b}{2} d_{\mathrm{r} 1}^{2}\right)=-\frac{a \lambda}{\rho_{\mathrm{m}} h_{\mathrm{f}}} \Delta t$.

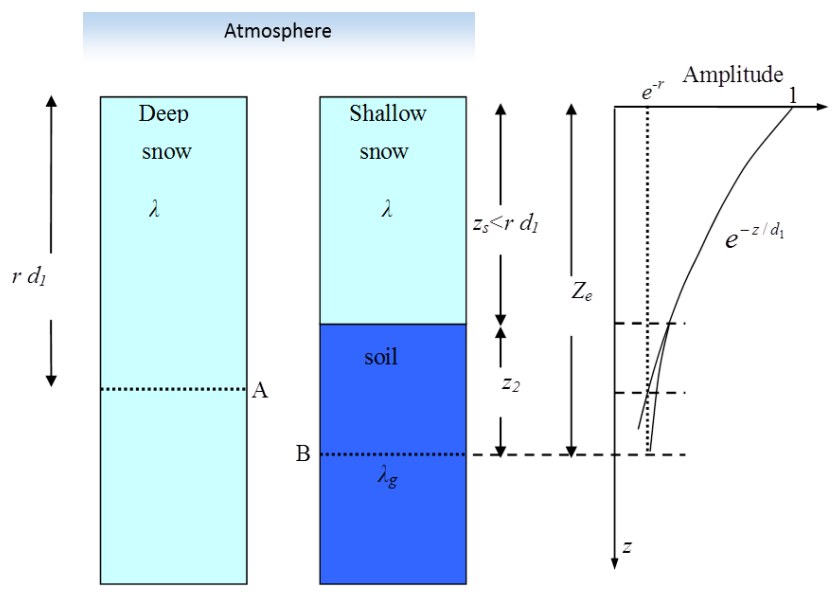

Figure 2. Heat conduction scheme for combined snow/soil system. The dashed lines at depths A and B indicate the depths at which temperature fluctuation amplitude is damped by $e^{-r}$ in the deep snow and combined snow/soil system, respectively.

This has the solution

$d_{\mathrm{r}}=\frac{-\lambda+\sqrt{\lambda^{2}+2 b\left(\lambda d_{\mathrm{r} 1}+\frac{b}{2} d_{\mathrm{r} 1}^{2}-\frac{a \lambda \Delta t}{\rho_{\mathrm{m}} h_{\mathrm{f}}}\right)}}{b}$.

Only the positive root has been retained since only positive values of $d_{\mathrm{r}}$ are physically interpretable and $b$ is a value greater than 0 . When $d_{\mathrm{r}}$ is greater than $\mathrm{rd}_{1}$, the effective depth associated with diurnal temperature fluctuations, or all meltwater is refrozen, the model reverts back to the surface temperature parameterization without refreezing of meltwater as described above.

\subsection{Adjustment of thermal conductivity, $\lambda$, for shallow snowpack}

In Eqs. (13), (21), (22) and (23) the temperature gradient is calculated over an effective depth $\left(Z_{\mathrm{e}}=\mathrm{rd}_{1}\right)$ estimated from the depth of penetration of surface temperature forcing at a diurnal frequency. When the snow is shallow, this depth may extend into the ground below the snow cover. In such cases, the thermal conductivity used in the surface temperature parameterizations above needs to reflect the combined conductivity of snow and soil below. We therefore take the effective thermal conductivity of the snowpack, $\lambda_{\mathrm{e}}$, as the harmonic mean to the effective depth, $Z_{\mathrm{e}}$, where the amplitude is damped by the same factor as it would be for deep snow (see Fig. 2). In deep snow the amplitude of diurnal temperature fluctuations at depth $Z_{\mathrm{e}}$ is damped by (Eq. 18) $e^{-Z_{\mathrm{e}} / d_{1}}=e^{-r}$. In the combined snow/soil system, given $r$, we first solve for the depth into the soil $z_{2}$ at which the amplitude of diurnal temperature fluctuations is damped by this same factor $e^{-r}$. Then $\lambda_{\mathrm{e}}$ is obtained by taking the harmonic mean to this depth. The thermal diffusivity of the ground below the snow, $k_{\mathrm{g}}$, is related to the thermal conductivity, $\lambda_{\mathrm{g}}$, 
heat capacity, $C_{\mathrm{g}}$, and density, $\rho_{\mathrm{g}}$, of the ground through

$k_{\mathrm{g}}=\frac{\lambda_{\mathrm{g}}}{C_{\mathrm{g}} \rho_{\mathrm{g}}}$.

The diurnal damping depth, $d_{\mathrm{g}}$, associated with this ground thermal diffusivity is

$d_{\mathrm{g}}=\sqrt{\frac{2 k_{\mathrm{g}}}{\omega_{1}}}$.

The amplitude of diurnal temperature fluctuation at depth $z_{2}$ into the ground, relative to the surface temperature fluctuation is therefore damped by $e^{-z_{\mathrm{s}} d_{1}} e^{-z_{2} / d_{\mathrm{g}}}$. Equating this to $e^{-r}$ we obtain

$\frac{z_{\mathrm{s}}}{d_{1}}+\frac{z_{2}}{d_{\mathrm{g}}}=r$.

Thus $z_{2}$ is

$z_{2}=d_{\mathrm{g}}\left(r-\frac{z_{\mathrm{s}}}{d_{1}}\right)$.

The effective thermal conductivity, $\lambda_{\mathrm{e}}$, and the effective depth, $Z_{\mathrm{e}}$, for the shallow snowpack are then estimated through the following:

$Z_{\mathrm{e}}=z_{\mathrm{s}}+z_{2}=z_{\mathrm{s}}+d_{\mathrm{g}}\left(r-\frac{z_{\mathrm{s}}}{d_{1}}\right)$,

$\frac{1}{\lambda_{\mathrm{e}}}=\frac{\frac{z_{\mathrm{s}}}{\lambda}+\frac{z_{2}}{\lambda_{\mathrm{g}}}}{Z_{\mathrm{e}}}$.

Eq. (40) is used to obtain the effective thermal conductivity near the surface when the snow is shallow. This is used in the parameterizations for surface temperature that calculate the surface heat flux between the snowpack and the atmosphere as well as conduction into the snow.

Summarizing our model improvements, the force restore and modified force restore approach have been included in the new surface UEB snowmelt model to better parameterize the surface temperature of snow. A new refreezing scheme was developed to model heat loss following partial melt through modeling the penetration of a refreezing front into the snowpack. The model was changed to adjust effective thermal conductivity used in the surface temperature parameterization for a shallow snowpack where the penetration depth for diurnal temperature fluctuations extends into the ground.

\section{Study sites and data}

The new surface UEB model was calibrated and tested using data from three locations in the western US.

\subsection{Utah State University drainage and evapotranspira- tion experimental farm}

The USU drainage and evapotranspiration experimental farm is located in Cache Valley near Logan, Utah, USA $\left(41.6^{\circ} \mathrm{N}\right.$, $111.6^{\circ} \mathrm{W}, 1350 \mathrm{~m}$ elevation). The weather station and instrumentation were in a small fenced enclosure at the center of an open field with no obstructions to wind in any direction for at least $500 \mathrm{~m}$. Cache Valley is a flat-bottomed valley surrounded by mountains that reach elevations of $3000 \mathrm{~m}$. During the period of this experiment the ground was snow covered from 20 November 1992 to 22 March 1993. Air temperatures ranged from -23 to $16^{\circ} \mathrm{C}$ and there was $190 \mathrm{~mm}$ of precipitation (mostly snow, but some rain). The snow accumulated to a maximum depth of $0.5 \mathrm{~m}$ with maximum water equivalent of $0.14 \mathrm{~m}$. Data collected included measurements of snow water equivalent, snow surface temperature, temperatures within the snowpack and the upper soil layer, and the meteorological variables necessary to drive UEB at $30 \mathrm{~min}$ time steps.

Shallow soil temperatures were measured using two thermocouples placed below the ground surface at depths of 25 and $75 \mathrm{~mm}$. Another thermocouple was placed at the ground surface. The snowpack temperature was measured using thermocouples suspended at 50,125, 200, 275 and $350 \mathrm{~mm}$ above the ground surface on fishing line strung between two upright posts. These temperature measurements were corrected for high frequency fluctuations in the panel reference temperature (Luce and Tarboton 2010). Snowpack surface temperature was measured with two Everest Interscience model 4000 infrared thermometers. Internal energy content of the snowpack was calculated from the temperature profile of the snowpack and upper soil layer accounting for the near surface nonlinearity through an analytic integral of Eq. (18) as described by Luce (2000), Luce and Tarboton (2010). Snow water equivalent was measured using a snow tube. Snow pits provided measurements of density and depth. On each measurement occasion snow water equivalent was measured at eight locations (fewer when snow had disappeared from some) and averaged.

A complete data set including the air temperature, wind speed, relative humidity, incident shortwave radiation, outgoing shortwave radiation, temperature profile through the snow and surface temperature of snowpack was available from 26 January 1993 to 22 March 1993 when the snow completely melted away. The data at the Utah State University drainage farm (USUDF) was used in this study to calibrate the new surface UEB model.

\subsection{Central Sierra Snow Laboratory}

The Central Sierra Snow Laboratory located $1 \mathrm{~km}$ east of Soda Springs, California, measures and archives comprehensive data relevant to snow. It is located at $39^{\circ} 19^{\prime} \mathrm{N}$, $120^{\circ} 22^{\prime} \mathrm{W}$, at an elevation of $2100 \mathrm{~m}$. The meteorological 
data are reported each hour and consist of temperature, radiation, humidity, precipitation, and wind measurements at two levels in a $40 \mathrm{~m}$ by $50 \mathrm{~m}$ clearing and in a mixed conifer canopy with $95 \%$ forest cover. Snow depths and water equivalent are measured daily (except on weekends) and eight lysimeters record melt outflow each hour. The data from the open site used in this study were collected between 14 November 1985 and 1 July 986 when the snowpack disappeared at the open site at a 6-hour time step. A total of 124 snow water equivalent measurements in addition to hourly lysimeter data were available for this time period. This data set was used to test the new surface UEB model.

\subsection{Niwot Ridge, Colorado}

Another data set used to test the new model comes from the subnivean snow laboratory at Niwot Ridge on the eastern slope of the Front Range of Colorado $(3517 \mathrm{~mm}$.s.l., $40^{\circ} 03^{\prime} \mathrm{N}, 105^{\circ} 35^{\prime} \mathrm{W}$ ) collected during the $1995-1996$ winter seasons. The instrument site is located in a relatively flat area above the treeline within a broad saddle of the ridge. The high elevation and exposure of Niwot Ridge, and typically dry atmospheric conditions, result in large clear-sky atmospheric transmissivity, high solar insolation, and low magnitudes of incident longwave radiation, low air temperatures, and high wind velocities. The data set includes measurements of air temperature, wind speed, relative humidity, and incident shortwave radiation from 28 April 1996 to 30 September 1996 with a time step of $2 \mathrm{~h}$. Measured lysimeter data are also available although there are concerns as to how representative it is due to preferential flow paths (finger flow) in the snow resulting in undercatch of meltwater (Cline, 1997a). This data set was used for further validation of the new surface UEB model in a setting with spatial variability and wind exposure.

\section{Results}

The new surface UEB model with the modified force-restore surface temperature parameterization was calibrated against the data from the USUDF to adjust some parameters and reflect the model changes. The model was then tested at the Central Sierra Snow Laboratory (CSSL) site. The model was validated using data from the Niwot ridge site, testing to some degree the physical basis and transferability of the model parameters.

At USUDF, Luce (2000) and Luce and Tarboton (2010) found evidence that the estimates of the incoming longwave radiation used in the original model testing (Tarboton et al., 1995; Tarboton and Luce, 1996) were too low due to frequent inversions during winter. Luce (2000) estimated the downward longwave radiation flux from the total snowpack energy balance during non-melt periods given all other energy components such as ground heat flux, net shortwave radiation,

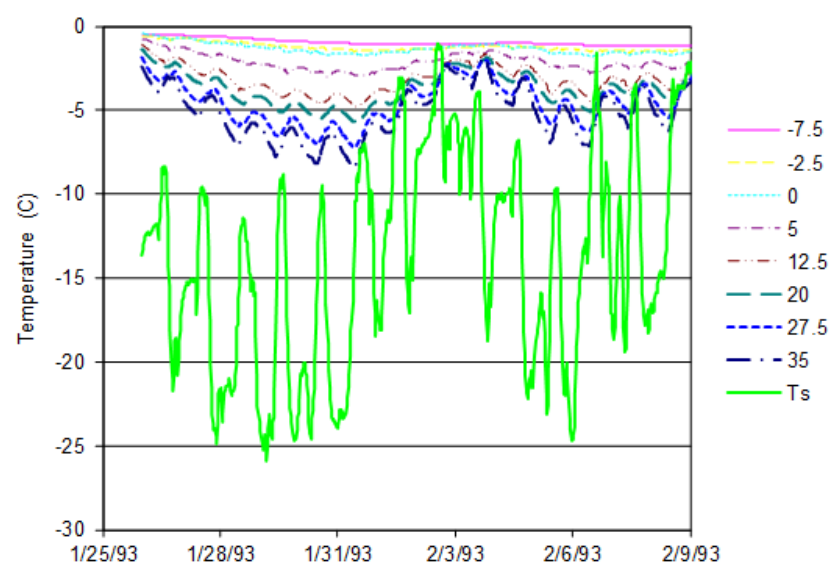

Figure 3. Measured snow, ground, and snow surface temperatures at the USU drainage farm. $T_{\mathrm{S}}$ is the measured surface temperature of snow from an infrared sensor. Other temperatures are from thermocouples labeled according to their height relative to the ground surface. Negative heights are below the ground surface and positive heights above the ground surface. 0 refers to the measured temperature at the ground surface.

turbulent fluxes and outgoing longwave radiation. The corrected longwave estimates were validated against cloud and fog observations at a nearby airport. In validating the new surface energy approximation, we used the measured shortwave radiation, the downward longwave radiation estimated by Luce (2000), and the measured ground heat flux to drive implementations of surface UEB with each of the three alternative surface temperature parameterizations given above (equilibrium gradient, force restore and modified force restore). The new surface model includes parameters from the original UEB model as well as new parameters introduced with the enhancements. Although there is some degree of circularity in using the total energy balance as an estimator of one stream of incoming energy, none of the alternative surface temperature parameterizations and none of the refreezing components were used in making the estimates. Consequently, comparisons among alternative model choices are nominally unaffected by the partially calibrated longwave radiation estimates at the USUDF location, and the results should be viewed in the context of a comparison for different approaches and incremental improvement rather than as a validation per se. Table 1 gives parameter values indicating which are new, and which were adjusted from their original UEB values to fit the data at USUDF as discussed below.

\subsection{Modeled internal energy of snow}

Figure 3 shows the time series of measured snow, ground and snow surface temperatures at the USU drainage farm that were used to calculate the internal energy content of the snowpack. Because this measured internal energy is only based on temperatures and does not account for any liquid 
Table 1. Model parameter values.

\begin{tabular}{|c|c|}
\hline Parameters & Value \\
\hline Thermal conductivity of snow $\lambda_{\mathrm{s}}$ & $0.33 \mathrm{~kJ} \mathrm{~m}^{-1} \mathrm{~K}^{-1} \mathrm{~h}^{-1} * *$ \\
\hline Thermal conductivity of soil $\lambda_{\mathrm{g}}$ & $6.5 \mathrm{~kJ} \mathrm{~m}^{-1} \mathrm{~K}^{-1} \mathrm{~h}^{-1} * *$ \\
\hline Low frequency forcing frequency $\omega_{\mathrm{lf}}$ & 0.0654 radians $h^{-1}\left(\omega_{1} / 4\right)^{* *}$ \\
\hline Dimensionless damping depth factor $r$ & $1 * *$ \\
\hline Threshold depth for fresh snow $d_{\text {NewS }}$ & $0.002 \mathrm{~m} * *$ \\
\hline Saturated hydraulic conductivity $K_{\text {sat }}$ & $200 \mathrm{mh}^{-1 *}$ \\
\hline Surface aerodynamic roughness $z_{\mathrm{o}}$ & $0.01 \mathrm{~m}^{*}$ \\
\hline Capillary retention fraction $L_{\mathrm{c}}$ & $0.02 *$ \\
\hline Soil effective depth $D_{\mathrm{e}}$ & $0.1 \mathrm{~m}^{*}$ \\
\hline Snow density $\rho_{\mathrm{s}}$ & $200 \mathrm{~kg} \mathrm{~m}^{-3} *$ \\
\hline Ground heat capacity $C_{\mathrm{g}}$ & $2.09 \mathrm{~kJ} \mathrm{~kg}^{-1} \mathrm{~K}^{-1}$ \\
\hline Density of soil layer $\rho_{\mathrm{g}}$ & $1700 \mathrm{~kg} \mathrm{~m}^{-3}$ \\
\hline Emissivity of snow $\varepsilon_{\mathrm{S}}$ & 0.99 \\
\hline Temperature above which precipitation is rain $T_{\mathrm{r}}$ & $3^{\circ} \mathrm{C}$ \\
\hline Temperature below which precipitation is snow $T_{\mathrm{sn}}$ & $-1^{\circ} \mathrm{C}$ \\
\hline Wind/air temperature measurement height $z_{\mathrm{m}}$ & $2 \mathrm{~m}$ \\
\hline Bare ground albedo $\alpha_{\mathrm{bg}}$ & 0.25 \\
\hline New snow near infrared band reflectance $\alpha_{\text {iro }}$ & $65 \%$ \\
\hline New snow visible band reflectance $\alpha_{\mathrm{vo}}$ & $85 \%$ \\
\hline
\end{tabular}

* These parameters were calibrated to have new values. ** These parameters are new, i.e., they were not present in the original UEB.

water present, measured internal energy content is only comparable to modeled internal energy during cold periods when liquid water is not present. During warm periods, the modeled energy content is expected to go above zero while measured energy content remains close to (just below) zero. The three approaches for surface temperature approximation described above were included as options in the new surface UEB. (The original UEB model only had the gradient approach). The comparisons between the modeled and measured internal energy values (Fig. 4) focus on periods when the snow is cold and liquid water is not present. These comparisons appear similar to the initial work of Luce (2000, Figs. 2-5) and Luce and Tarboton $(2001,2010)$ that indicates that the modified force restore snow surface temperature approximation compares best to the internal energy content of snowpack. Here we note that these results differ from the earlier work of Luce (2000) and Luce and Tarboton (2001, 2010) in that the new results are complete model simulations driven by inputs of air temperature, humidity, radiation and wind with surface temperature calculated by the model. The earlier work used the measured surface temperature to drive calculations of internal energy estimating only the conduction into the snow, which does not test interactions of the new scheme with energy fluxes dependent on surface temperature. The results here are from a free running model forced by weather inputs that do test the modeling of dynamic interactions among the surface energy exchanges and surface temperature. Some parameters and physical properties quantified earlier (Luce and Tarboton, 2001, 2010) were used here.

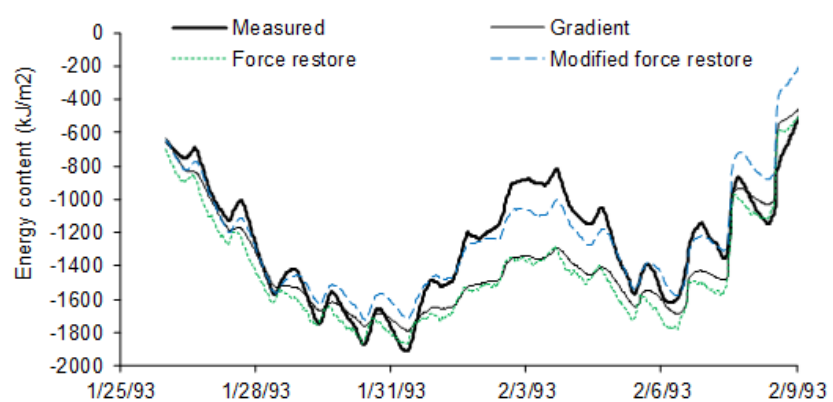

Figure 4. Comparisons of internal energy of snowpack during the first 2 freezing weeks at the USU drainage farm. Measured is the internal energy of snowpack calculated from the temperature profile (Fig. 3). Gradient, Force restore, and Modified force restore represent the modeled internal energy of snowpack using the equilibrium approach, the force-restore approach, and the modified force restore approach, respectively.

Following the success of the modified force-restore surface temperature approach relative to the other approaches at the USUDF, the modified force restore was used in all subsequent evaluations at the other sites.

Comparisons between modeled and measured variables at USUDF are shown in Figs. 5, 6, 7, and 8. Figure 5 includes measured snow water equivalent and the results from five model runs. Four model runs are from the new surface UEB model using the parameters listed in Table 1, each initialized on a different date indicated by the letters (a) through (d) following periods of severe weather and likely erroneous inputs. 


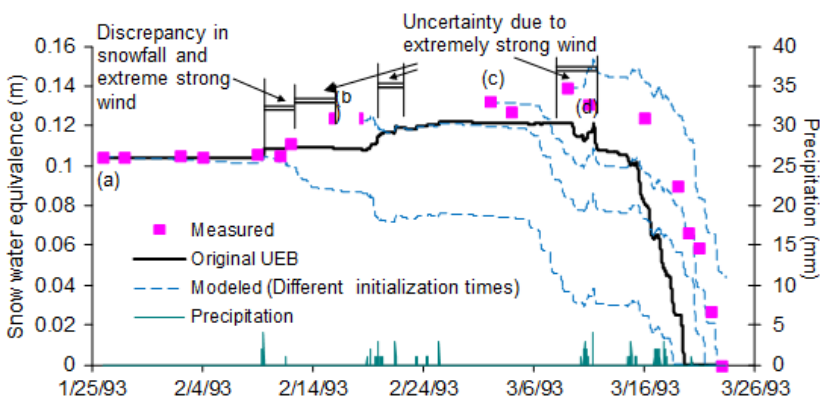

Figure 5. Comparisons of snow water equivalent in 1993 at the USU drainage farm. The dashed lines are the modeled values with new model starts at different times. Precipitation input is shown (spiky line at the bottom) relative to the axis at the right. Letters (a) through (d) indicate points where the model was re-initialized following periods of likely erroneous inputs due to severe weather.

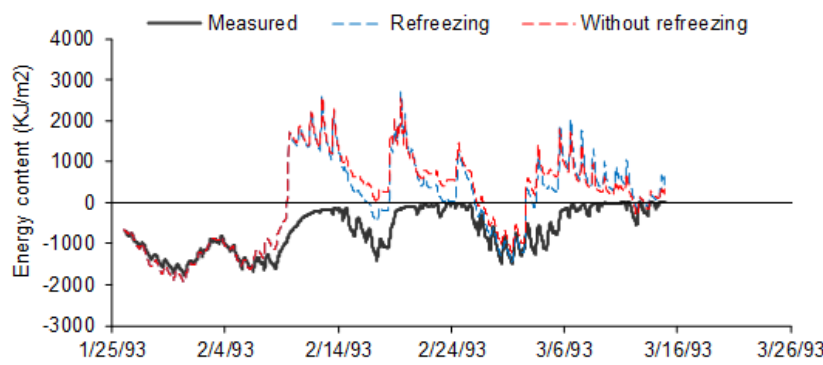

Figure 6. Comparisons of internal energy of snowpack in 1993 at the USU drainage farm. The wide solid line is the measured values. "Refreezing" represents the modeled internal energy of snowpack with new surface UEB model. "Without refreezing" represents the model without the refreezing scheme.

The fifth model run is from the original UEB model with its original parameters reported by Tarboton (1994). Figure 6 shows the measured and modeled energy content from the new surface UEB model run initialized on 26 January 1993 together with a model run using the code prior to the addition of the refreezing parameterization. Note that with the addition of the refreezing parameterization, lower energy content better in line with measurements is obtained than without the refreezing parameterization.

Figure 7 shows measured and modeled energy content from the original UEB model, indicating a large discrepancy in energy content. This problem was identified by this comparison to internal energy computed from temperature profile measurements (Fig. 3). This discrepancy has been resolved (Fig. 6) through the combination of modifications reported in this paper (modified force restore, surface refreezing and shallow snow conductivity adjustment). These results point to the importance of comparing models to measurements of their internal state as without the direct comparison to energy content the discrepancy with the original UEB may not have been identified.

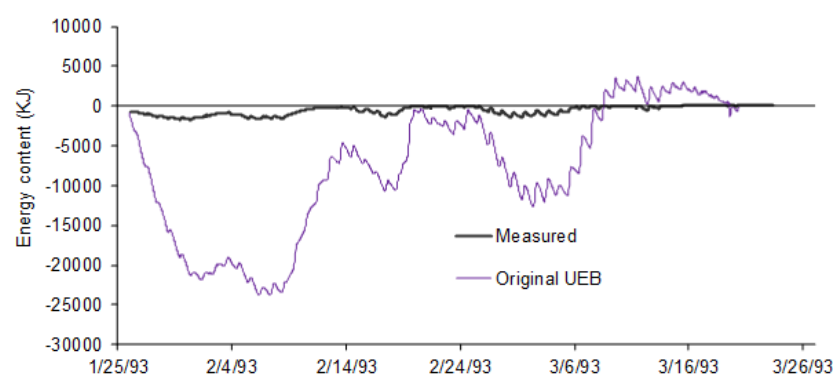

Figure 7. Comparisons between the measured and modeled internal energy of the snowpack at the USU drainage farm in the original model.
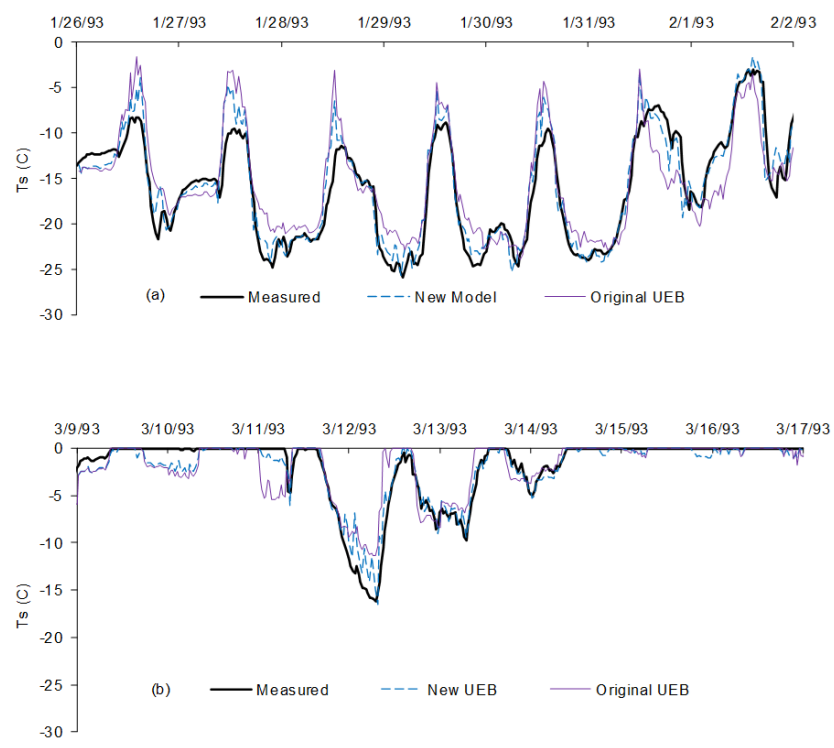

Figure 8. Comparisons of snow surface temperature in 1993 at the USU drainage farm. (a) the first 2 subfreezing weeks, and (b) end of the modeling period when the snowpack is occasionally in an isothermal state.

\subsection{Modeled snow water equivalent and meltwater}

Figure 8 shows surface temperature comparisons for two time intervals chosen to be illustrative of periods prior to the onset of melt and during the period when snow is melting. The model runs shown in Fig. 8a were initialized on 26 January 1993. The original UEB model run shown in Fig. $8 \mathrm{~b}$ is the same as in Fig. 8a while the new surface UEB model run shown was initialized on 9 March 1993. Note that these surface temperature comparisons, such as were used in the development of the original UEB do not indicate the energy discrepancy that full profile temperature measurements reveal.

The new surface UEB model and the calibrated model parameters were then tested using the 1985-1986 data from the CSSL, CA. Comparisons of the modeled and the measured variables are shown in Figs. 9, 10, 11, and 12. The modeled 


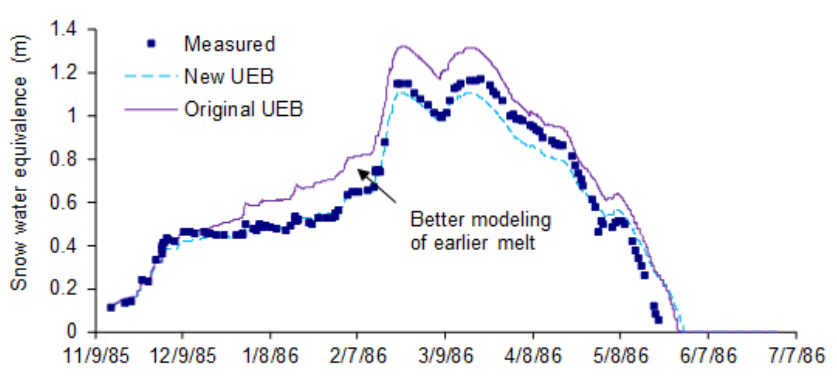

Figure 9. Comparisons of snow water equivalent in 1986 at CSSL.

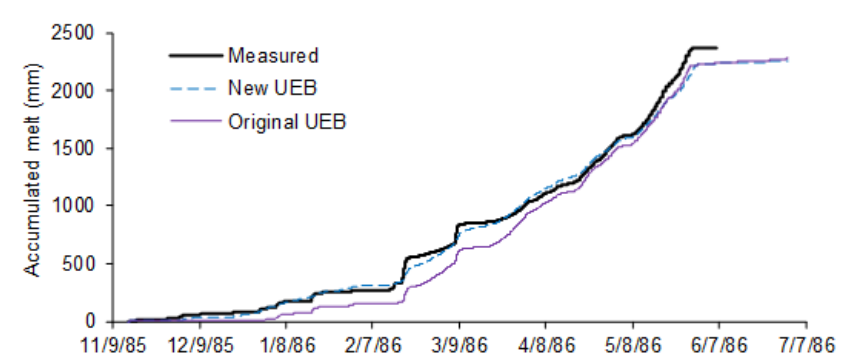

Figure 10. Comparisons of accumulative melt in 1986 at CSSL.

results fit the measurements well. The discussion section further examines these results.

The new surface UEB model was also tested using 1996 data from the subnivean snow laboratory at Niwot Ridge, CO. Modeled and observed snow water equivalent are compared in Fig. 13. The model was initialized with the beginning observed snow water equivalent value of $1.4 \mathrm{~m}$. Melt outflows that totaled to $0.23 \mathrm{~m}$ were recorded. These were used to infer the snow water equivalent back through time. However, as shown in Fig. 13, there is a discrepancy between the measured total melt $(0.23 \mathrm{~m})$ and observed initial snow water equivalent $(1.4 \mathrm{~m})$. This is presumed to be due to preferential meltwater drainage flow paths in the snow as reported previously at this location (Cline, 1997b). An adjustment factor was calculated as $\frac{W_{\text {ini }}+\sum p}{\sum m}$, where $W_{\text {ini }}$ is the initial measured snow water equivalent, $\sum p$ is the total precipitation during the modeling time, and $\sum m$ is the total measured meltwater outflow.

\subsection{Modeled albedo}

The USUDF instrumentation included a net radiometer and downward and upward pointing pyranometers. These were used to obtain a measured estimate of Albedo that was compared to albedo as simulated by the original model and new surface UEB model (Fig. 14). These results indicated that albedo was not being refreshed to new snow values following snowfall. This was corrected by changing the threshold of new snow water equivalent that restores albedo to the new snow cover, $d_{\mathrm{NewS}}$, to $0.002 \mathrm{~m}$; this was previously $0.01 \mathrm{~m}$.

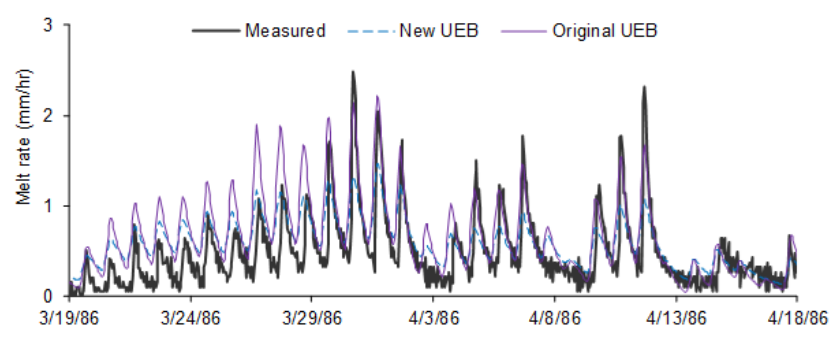

Figure 11. Comparisons of meltwater outflow rate in 1986 at CSSL.

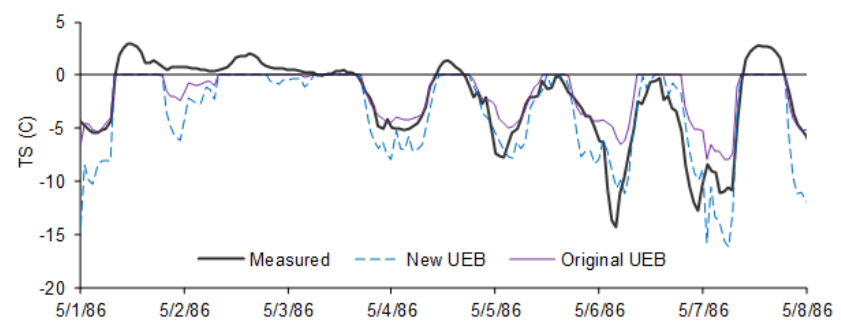

Figure 12. Comparisons of surface temperature of snow in 1986 at CSSL.

\section{Discussion}

The most significant change introduced into the surface UEB model was the change to the surface temperature parameterization. Figure 9 shows the snow water equivalent data originally used to validate the UEB model, together with surface temperature comparisons, such as Fig. 8 and melt outflow comparisons such as Fig. 10. These results looked satisfactory at the time, but once measurements of internal energy (Fig. 7) were obtained it was realized that the original UEB had problems representing internal energy and this deficiency was traced in part to the surface temperature parameterization (Luce and Tarboton, 2010). Incorporating the modified force restore approach they suggested into the UEB model resulted in improvements in snowpack internal energy estimates (Fig. 4).

Density and thermal conductivity are the primary parameters introduced in the new parameterization of surface temperature (Eqs. 21, 22 and 23). Variability in thermal conductivity as a function of snow density is to be expected as both are determined by the snow's microstructure but are not uniquely related to each other. Measurements of the thermal conductivity of snow are thoroughly reviewed by Sturm et al. (1997). In the literature there is variability in the values reported for thermal conductivity (Anderson, 1976; Gray and Male, 1981; Lee, 1980). Anderson (1976, p. 30, Fig. 3.1) shows that the thermal conductivity of the snowpack may change over a wide range from 0.15 to $7.5 \mathrm{~kJ} \mathrm{~m}^{-1} \mathrm{~h}^{-1} \mathrm{~K}^{-1}$ at a density of $200 \mathrm{~kg} \mathrm{~m}^{-3}$. Lee (1980) also reported a range from $0.25 \mathrm{~kJ} \mathrm{~m}^{-1} \mathrm{~h}^{-1} \mathrm{~K}^{-1}$ at a density of $100 \mathrm{~kg} \mathrm{~m}^{-3}$ to $5.3 \mathrm{~kJ} \mathrm{~m}^{-1} \mathrm{~h}^{-1} \mathrm{~K}^{-1}$ at a density of $700 \mathrm{~kg} \mathrm{~m}^{-3}$. Gray and Male (1981) indicated that thermal conductivity changes 


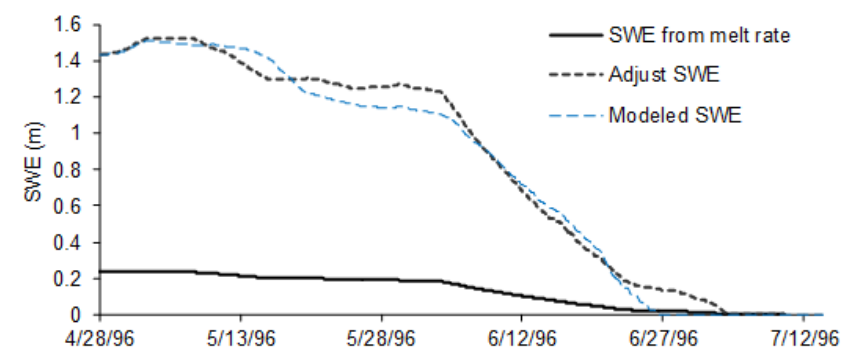

Figure 13. Comparisons of snow water equivalent in 1996 at the subnivean snow laboratory at Niwot Ridge watershed, CO.

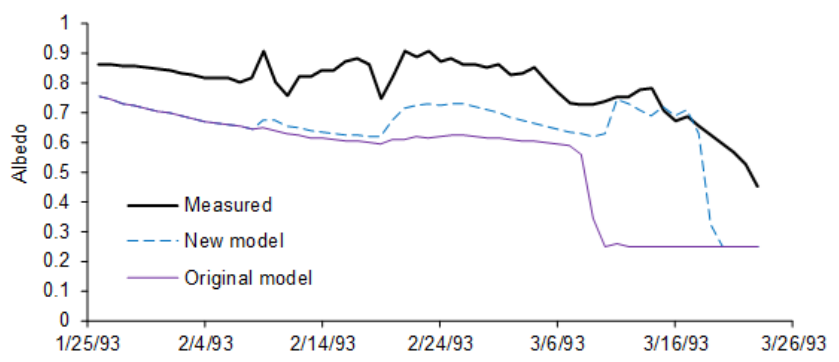

Figure 14. Comparison of measured and modeled albedo at the USU drainage farm.

are nonlinear from $0.18 \mathrm{~kJ} \mathrm{~m}^{-1} \mathrm{~h}^{-1} \mathrm{~K}^{-1}$ at a density of about $175 \mathrm{~kg} \mathrm{~m}^{-3}$ to $5.76 \mathrm{~kJ} \mathrm{~m}^{-1} \mathrm{~h}^{-1} \mathrm{~K}^{-1}$ at a density of $800 \mathrm{~kg} \mathrm{~m}^{-3}$. The UEB model retains a degree of simplicity by not modeling surface density and thermal conductivity as time varying quantities. The surface UEB uses a single thermal conductivity value and snow density, and the values of $\lambda_{\mathrm{s}}=0.33 \mathrm{~kJ} \mathrm{~m}^{-1} \mathrm{~h}^{-1} \mathrm{~K}^{-1}$ and $\rho_{\mathrm{s}}=200 \mathrm{~kg} \mathrm{~m}^{-3}$ were calibrated to fit the internal energy measurements of Fig. 4 considering the snow thermal properties inferred from frequency analysis by Luce and Tarboton (2010). Snow density is reflective of the density of the snow surface, involved in surface energy exchanges, rather than the snowpack as a whole. Modeling the thermal conductivity as a function of density may improve the performance of snowmelt models (if the density was able to be appropriately modeled). However, the errors in modeling the density may introduce errors in modeling the surface heat conduction and the internal energy content.

A value of $r=1$ was used for the dimensionless damping depth factor. This nominal value corresponds to a gradient over the depth to which diurnal temperature fluctuations are attenuated by a factor of $1 / e$. The soil thermal conductivity parameter also plays a role in the model when the snowpack is shallow (Eq. 40) and was set to a value of $6.5 \mathrm{~kJ} \mathrm{~m}^{-1} \mathrm{~h}^{-1} \mathrm{~K}^{-1}$, within the range of soil heat conductivity reported for the Logan Area (Hanks and Ashcroft, 1980; Luce, 2000). The low frequency forcing frequency value, $w_{\mathrm{lf}}$, was set to $0.0654 \mathrm{rad} \mathrm{h}^{-1}$ based on Luce and Tarboton (2010).
It is interesting to note that with a new surface temperature parameterization calibrated to USUDF data, the model better represents the CSSL snow water equivalent data (Fig. 9) and cumulative melt data (Fig. 10) early in the season. This model successfully resolves the failure to capture earlyseason melt, a problem which is a fairly common feature of single-layer models (Slater et al., 2001). The model now holds energy content closer to zero and is able to represent early season melt, correcting the relatively small early season discrepancy in comparisons to CSSL data that was present in the original UEB model calibrations. Small discrepancies still exist in the modeled snow water equivalent and the measurement snow water equivalent at the high accumulation period. This may be due to remaining model errors and some uncertainty (undercatch) in the snowfall measurements that are inputs. The disappearance date of the snow at CSSL was still modeled about 1 week later than the observed, which may be due to errors in modeling the decrease of albedo perhaps due to contamination of the snow or due to the increase of longwave radiation from the nearby forest canopy.

Representation of observed snow water equivalent at USUDF in a single model run proved to be difficult. We attributed this to uncertainty and likely erroneous input quantities during windy and stormy severe weather periods. Snowfall was recorded in a heated unshielded precipitation gauge so is uncertain and likely to suffer from undercatch. There was also snow drifting resulting in accumulation and scour associated with strong winds, and griming of the instruments recording radiation.

One of the problems discovered with the original UEB model was that it offsets the bias due to the surface temperature parameterization by a bias in heat loss following surface melting (Fig. 6). Following a period of snowmelt, the observed energy content is observed to fall below 0 but the modeled energy content remained above 0 . Without the refreezing parameterization surface temperature immediately drops in a cooling period, limiting the heat loss by reducing the outgoing longwave radiation. The parameterization of the refreezing front corrected this to some extent (Fig. 6) keeping the surface temperature warmer and sustaining greater outgoing longwave radiation energy losses, the extra energy loss going to refreeze liquid water present and allowing the model energy content to drop more in line with the observations.

Melt outflow rates were not measured at USUDF. The changes in surface temperature and refreezing parameterization changed the modeled amount of liquid water, which changed melt outflow. We used measured melt outflow at CSSL (Fig. 11) to adjust the snow hydraulic conductivity to $200 \mathrm{~m} \mathrm{~h}^{-1}$, a value still within the range from 20 to $300 \mathrm{~m} \mathrm{~h}^{-1}$ reported in the literature (Gray and Male, 1981). Liquid holding capacity was adjusted to 0.02 to better fit melt outflow.

$D_{\mathrm{e}}$ and $z_{0}$ were adjusted based on the research of Luce (2000) and Luce and Tartboton (2010), where a value of 
$0.1 \mathrm{~m}$ was suggested for the soil effective depth and a value $0.01 \mathrm{~m}$ suggested for the surface aerodynamic roughness of snow $z_{0}$ in the calculation of turbulent heat flux.

The Albedo measurements at USUDF enabled refinement of the parameter quantifying the new snow water equivalent that restores albedo to the new snow cover, resulting in a more responsive modeling of albedo, consistent with observations (Fig. 14). However, there is an offset between modeled and observed albedo in this figure, which, we believe, is due to downward pointing limited-band pyranometers not being appropriate for measuring snow reflectance. However they do still provide us with relative measurements useful in quantifying the timing and responsiveness of albedo changes.

As was observed at the USU drainage farm, the new surface model also gave a good approximation of the surface temperature of snow (Fig. 12) at the CSSL snow laboratory. Both the new model and the original model perform well in approximating the surface temperature of snow at CSSL site. However, the new model corrects the offsets between the modeling of snow surface temperature and the modeling of the internal energy of the snowpack in the original model. Here we note that uncertainties exist in the measurements, e.g., the measurement of surface temperature of snow has positive value during some daytime periods.

The comparison between modeled and measured snow water equivalent at Niwot Ridge inferred from observed initial snow water equivalent and melt outflow is given in Fig. 13. This shows that after the adjustment to correct the discrepancy between initial snow water equivalent and measured melt, the back-calculated snow water equivalent compares well with modeled snow water equivalent. Due to the adjustment involved this is really only a check on the timing of the ablation.

\section{Conclusions}

This paper has (1) evaluated the force restore and modified force restore temperature parameterizations developed for a single layer snowmelt model in a complete energy balance free-running model driven by only atmospheric forcing; (2) introduced and evaluated a new parameterization for the refreezing of liquid water near the surface in an energy balance snowmelt model; and (3) introduced a refinement to adjust thermal conductivity parameters for shallow snowpacks. Collectively these contributions have solved the issue of overestimating the energy loss of snowpack and underestimating the average snow temperature in an earlier version of the UEB snowmelt model. With these refinements, the model was better able to represent internal energy content, snow surface temperature, early and late season snowmelt and albedo quite well. Through this modeling work the understanding of snow surface energy exchanges and how they can be more effectively modeled has improved.
This work has integrated information from a number of measurement sources to validate and improve parameterization of processes in the model. Without the temperature profile measurements that quantified internal energy, the energy content discrepancy would have been hard to identify.

The new surface UEB snowmelt model has been calibrated and tested against data sets from the USU drainage farm and CSSL snow laboratory and performed well at these two sites. The paper also included tests against some data from Niwot ridge, Colorado. However some discrepancies still exist between the modeled variables and the observations. Also some variables cannot be strictly compared or compared against a complete data set. A more complete data set of the liquid water content, together with continuous observation of snow water equivalent, snow surface temperature, melt, and depth, is necessary for a comprehensive test of the model improvements given here. This speaks to the need for integrated measurements of multiple variables at each of multiple sites to more fully constrain snow mass and energy processes to further improve snow models. Such data sets are becoming available (Morin et al., 2012) and it is important for future studies to take advantage of such data sets, and for more of such data sets to be collected.

Surface UEB is a single layer model designed to be parsimonious, yet use physically based calculations for the energy and mass exchanges at the snow surface so as to be transferable, with limited calibration, to other locations. This transferability was evaluated to a limited extent in this paper by using multiple somewhat geographically dispersed test sites in Utah, Colorado and California. The results thus provide some level of confidence in the transferability of the model, though further testing at additional sites would add to the confidence in the model transferability, or lead to further improvements. Surface UEB uses a limited number of state variables so as to be easy to apply in a spatially distributed fashion. It focuses on surface energy exchanges and surface temperature as the variable at the interface between the surface and atmosphere governing energy exchanges. It avoids attempting to represent the internal energy exchanges between snowpack layers thereby avoiding the introduction of errors due to the challenges in representing these complex internal snow processes. UEB compared favorably against more complex layered models in a recent model intercomparison (Rutter et al., 2009). Further evaluation of surface UEB together with other models in different climate and topographic settings, as suggested in Rutter et al. (2009), should be pursued.

Acknowledgements. This work was supported by NASA Land Surface Hydrology Program, grant number NAG 5-7597. The views and conclusions expressed are those of the authors and should not be interpreted as necessarily representing official policies, either expressed or implied, of the US government.

Edited by: C. De Michele 


\section{References}

Anderson, E. A.: A Point Energy and Mass Balance Model of a Snow Cover. NOAA Technical Report NWS 19, US Department of Commerce, 150 pp., 1976.

Berg, P. W, and McGregor, J. L.: Elementary Partial Differential Equations, Holden-Day, Oakland, 1966.

Blöschl, G. and Kirnbauer, R.: Point snowmelt models with different degrees of complexity - internal processes, J. Hydrol., 129, 127-147, 1991.

Bras, R. L.: Hydrology, an Introduction to Hydrologic Science, Addison-Wesley: Reading, MA, 1990.

Bristow, K. L, and Campbell, G. S.: On the relationship between incoming solar radiation and the daily maximum and minimum temperature, Agr. Forest Meteorol., 31, 159-166, 1984.

Cline, D. W.: Snow surface energy exchanges and snowmelt at a continental, midlatitude alpine site, Water Resour. Res., 33, 689701, 1997a.

Cline, D. W.: Effect of seasonality of snow accumulation and melt on snow surface energy exchanges at a continental alpine site, J. Appl. Meteorol., 36, 22-41, 1997b.

Colbeck, S. C and Anderson, E. A.: The Permeability of a Melting Snow Cover, Water Resour. Res., 18, 904-908, 1982.

Deardorff, J. W.: Dependence of Air-Sea Transfer Coefficients on Bulk Stability, J. Geophys. Res., 73, 2549-2557, 1968.

Deardorff, J. W.: Efficient prediction of ground surface temperature and moisture with inclusion of a layer of vegetation, J. Geophys. Res., 83, 1889-1903, 1978.

Dickinson, R. E, Henderson-Sellers, A., and Kennedy, P. J.: Biosphere-Atmosphere Transfer Scheme (BATS) Version 1e as Coupled to the NCAR Community Climate Model. NCAR/TN387+STR, National Center for Atmospheric Research. Boulder, CO, 71 pp., 1993.

Dingman, S. L.: Physical Hydrology, Macmillan, New York, 1994.

Dozier, J.: Spectral Signature of Alpine Snow Cover from the Landsat Thematic Mapper, Remote Sens. Environ., 28, 9-22, 1989.

Dyer, A. J. and Hicks, B. B.: Flux-gradient Relationships in the Constant Flux Layer, Quart. J. R. Met. Soc., 96, 715-721, 1970.

Eiriksson, D., Whitson, M., Luce, C. H., Marshall, H. P., Bradford, J., Benner, S. G., Black, T., Hetrick, H., and McNamara, J. P.: An evaluation of the hydrologic relevance of lateral flow in snow at hillslope and catchment scales, Hydrol. Process., 27, 640-654, doi:10.1002/hyp.9666, 2013.

Flerchinger, G. N. and Saxton, K. E.: Simultaneous Heat and Water Model of a Freezing Snow-Residual- Soil System I. Theory and Development, Trans. ASAE, 32, 565-571, 1989.

Gray, D. M. and Male, D. H. (Eds): Handbook of Snow, Principles, Processes, Management \& Use, Pergamon Press: New York, 1981.

Hanks, R. J. and Ashcroft, G. L.: Applied Soil Physics, Vol. 8, Advanced Series in Agricultural Sciences, Springer-Verlag: Berlin Heidelberg, 1980.

Higuchi, K. and Tanaka, Y.: Flow pattern of meltwater in mountain snow cover, Hydrological aspects of alpine and high-mountain areas, Hydrol. Sci. J., 27, p. 256, 1982.

$\mathrm{Hu}, \mathrm{Z}$. and Islam, S.: Prediction of ground surface temperature and soil moisture content by the force-restore method, Water Resour. Res., 31, 2531-2539, 1995.
Jordan, R.: A One-dimensional Temperature Model for a Snow Cover. Technical documentation for SNTHERM.89, special technical report 91-16, US Army CRREL, 49 pp., 1991.

Kattelmann, R. and Dozier, J.: Observations of snowpack ripening in the Sierra Nevada, California, USA, J. Glaciol., 45, 409-416, 1999.

Koivasulo, H. and Heikenkeimo, M.: Surface energy exchange over a boreal snowpack, Hydrol. Process., 13, 2395-2408, 1999.

Lee, R.: Forest Hydrology, Columbia University Press, New York, 1980.

Linsley, R. K., Kohler, M. A., and Paulhus, J. L. H.: Hydrology for Engineers, 2nd Edn., McGraw-Hill: Kogakusha, Ltd., 1975.

Lowe, P. R.: An approximating polynomial for the computation of saturation vapour pressure, J. Appl. Meteorol., 16, 100-103, 1977.

Luce, C. H.: Scale influences on the representation of snowpack processes. Ph. D Dissertation, Civil and Environmental Engineering: Utah State University, Logan, Utah. 2000.

Luce, C. H, and Tarboton, D. G.: A modified force-restore approach to modeling snow-surface heat fluxes, in: Proceedings of the 69th Annual Meeting of the Western Snow Conference, Sun Valley, Idaho, available at: http://www.westernsnowconference.org/ 2001/2001 papers.htm (last access: 31 July 2004), 2001.

Luce, C. H., Tarboton, D. G., and Cooley, K. R.: The influence of the spatial distribution of snow on basin-averaged snowmelt, Hydrol. Process., 12, 1671-1683, 1998.

Luce, C. H. and Tarboton, D. G.: Evaluation of alternative formulae for calculation of surface temperature in snowmelt models using frequency analysis of temperature observations, Hydrol. Earth Syst. Sci., 14, 535-543, doi:10.5194/hess-14-535-2010, 2010.

Mahat, V. and Tarboton, D. G.: Canopy radiation transmission for an energy balance snowmelt model, Water Resour. Res., 48, W01534, doi:10.1029/2011WR010438, 2012.

Mahat, V., Tarboton, D. G., and Molotch, N. P.: Testing above and below canopy representations of turbulent fluxes in an energy balance snowmelt model, Water Resour. Res., 49, 1107-1122, doi:10.1002/wrcr.20073, 2013.

Morin, S., Lejeune, Y., Lesaffre, B., Panel, J.-M., Poncet, D., David, P., and Sudul, M.: An 18-yr long (1993-2011) snow and meteorological dataset from a mid-altitude mountain site (Col de Porte, France, $1325 \mathrm{~m}$ alt.) for driving and evaluating snowpack models, Earth Syst. Sci. Data, 4, 13-21, doi:10.5194/essd-4-13-2012, 2012.

Price, A. G. and Dunne, T.: Energy balance computations of snowmelt in a subarctic area, Water Resour. Res., 12, 686-694, 1976.

Rutter, N., Essery, R., Pomeroy, J., Altimir, N., Andreadis, K., Baker, I., Barr, A., Bartlett, P., Boone, A., Deng, H., Douville, H., Dutra, E., Elder, K., Ellis, C., Feng, X., Gelfan, A., Goodbody, A., Gusev, Y., Gustafsson, D., Hellström, R., Hirabayashi, Y., Hirota, T., Jonas, T., Koren, V., Kuragina, A., Lettenmaier, D., Li, W.-P., Luce, C., Martin, E., Nasonova, O., Pumpanen, J., Pyles, R. D., Samuelsson, P., Sandells, M., Schädler, G., Shmakin, A., Smirnova, T. G., Stähli, M., Stöckli, R., Strasser, U., Su, H., Suzuki, K., Takata, K., Tanaka, K., Thompson, E., Vesala, T., Viterbo, P., Wiltshire, A., Xia, K., Xue, Y., and Yamazaki, T.: Evaluation of forest snow processes models (snowmip2), J. Geophys. Res., 114, D06111, doi:10.1029/2008JD011063, 2009. 
Satterlund, D. R.: An improved equation for estimating long-wave radiation from the atmosphere, Water Resour. Res., 15, 16431650, 1979.

Slater, A. G., Schlosser, C. A., Desborough, C. E., Pitman, A. J., Henderson-Sellers, A., Robock, A., Vinnikov, K. Y., Entin, J., Mitchell, K., Chen, F., Boone, A., Etchevers, P., Habets, F., Noilhan, J., Braden, H., Cox, P. M., de Rosnay, P., Dickinson, R. E., Yang, Z. L., Dai, Y. J., Zeng, Q., Duan, Q., Koren, V., Schaake, S., Gedney, N., Gusev, Y. M., Nasonova, O. N., Kim, J., Kowalczyk, E. A., Shmakin, A. B., Smirnova, T. G., Verseghy, D., Wetzel, P., and Xue, Y.: The representation of snow in land surface schemes: Results from PILPS 2(d), J. Hydrometeorol., 2, 7-25, doi:10.1175/1525-7541(2001)002<0007:trosil>2.0.co;2, 2001.

Sturm, M., Holmgren, J., König, M., and Morris, K.: The thermal conductivity of seasonal snow, J. Glaciol., 43, 26-41, 1997.

Tarboton, D. G.: Measurement and modeling of snow energy balance and sublimation from snow, in: Proceedings of International Snow Science Workshop, Snowbird, Utah, 31 October to 2 November, 260-279, 1994.

Tarboton, D. G., Chowdhury, T. G., and Jackson, T. H.: A spatially distributed energy balance snowmelt model, in: Proceedings of a Boulder Symposium, Tonnessen KA, Williams MW, edited by: Tranter, M., Boulder, CO, 3-14 July, IAHS Publ. no. 228, 1995.

Tarboton, D. G. and Luce, C. H.: Utah Energy Balance Snow Accumulation and Melt Model (UEB). Computer model technical description and users guide, Utah Water Research Laboratory and USDA Forest Service Intermountain Research Station, available at: http://www.engineering.usu.edu/dtarb/ (last access: 31 July 2004), 1996.
US Army Corps of Engineers.: Snow Hydrology, Summary Report of the Snow Investigations, U.S. Army Corps of Engineers, North Pacific Division, Portland, Oregon, 142 pp., 1956.

Viessman, W., Lewis, G. L., and Knapp, J. W.: Introduction to Hydrology, 5th Edn., Prentice Hall New York, 2002.

Vionnet, V., Brun, E., Morin, S., Boone, A., Faroux, S., Le Moigne, P., Martin, E., and Willemet, J.-M.: The detailed snowpack scheme Crocus and its implementation in SURFEX v7.2, Geosci. Model Dev., 5, 773-791, doi:10.5194/gmd-5-773-2012, 2012.

Wankiewicz, A.: A review of water movement in snow, in: Proceedings: Modeling of snow cover runoff, edited by: Colbeck, S. C. and Ray, M., US Army Cold Regions Research and Engineering Laboratory, Hanover, New Hampshire, 1979.

Wever, N., Fierz, C., Mitterer, C., Hirashima, H., and Lehning, M.: Solving richards equation for snow improves snowpack meltwater runoff estimations in detailed multi-layer snowpack model, The Cryosphere, 8, 257-274, doi:10.5194/tc-8-257-2014, 2014.

Williams, M. W., Erickson, T. A., and Petrzelka, J. L.: Visualizing meltwater flow through snow at the centimetre-to-metre scale using a snow guillotine, Hydrol. Process., 24, 2098-2110, doi:10.1002/hyp.7630, 2010.

Yen, Y.C.: The rate of temperature propagation in moist porous mediums with particular reference to snow, J. Geophys. Res., 72, 1283-1288, 1967.

You, J.: Snow hydrology: The parameterization of subgrid processes within a physically based snow energy and mass balance model, PhD thesis, Utah State Univ., Logan, 2004 